\title{
Computed tomography scan efficacy in staging gastric linitis plastica lesion: a retrospective multicentric French study
}

This article was published in the following Dove Press journal:

Cancer Management and Research

\section{Stéphanie Morgant ${ }^{1}$ \\ Pascal Artru² \\ Ammar Oudjit ${ }^{3}$ \\ Nelson Lourenco ${ }^{4}$ \\ Arnaud Pasquer ${ }^{5}$ \\ Thomas Walter ${ }^{6}$ \\ Jean-Marc Gornet ${ }^{4}$ \\ Alexandre Rouquette ${ }^{7}$ \\ Gérard Lledo² \\ Catherine Brezault ${ }^{1}$ \\ Romain Coriat' \\ 'Gastroenterology and Digestive Oncology Unit, Cochin \\ Teaching Hospital, Paris, France; \\ ${ }^{2}$ Gastroenterology and Digestive Unit, Jean Mermoz Clinic, Lyon, \\ France; ${ }^{3}$ Radiology Unit, Cochin Teaching Hospital, Paris, France; ${ }^{4}$ Gastroenterology Unit, Saint-Louis Teaching Hospital, Paris, France; ${ }^{5}$ Digestive Surgery Unit, Edouard Herriot Teaching Hospital, Lyon, France; ${ }^{6}$ Oncology Unit, Edouard Herriot Teaching Hospital, Lyon, France; ${ }^{7}$ Pathology Department, Cochin Teaching Hospital, Paris, France}

Correspondence: Romain Coriat Gastroenterology and Digestive Oncology Unit, Hôpital Cochin, 27 Rue du Faubourg Saint-Jacques, 75014 Paris, France

Tel +33 | 584 | 1952

Fax +33 । 58 4| $4 \mid 55$

Email romain.coriat@aphp.fr
Background: Computed tomography (CT) scan is a key imaging technique in the staging of gastric adenocarcinoma and therapeutic management of patients. The aim of this study was to evaluate the performance of CT scan in the staging of parietal and metastatic invasion in gastric linitis plastica group.

Methods: A retrospective multicentric French study was conducted from January 2006 to December 2015 on patients with no metastatic gastric linitis plastica and operated by gastrectomy. A 2/1 matching based on pTNM stage and center was performed.

Results: Fifty patients were included in the linitis plastica group and 100 in the control group. Patients from the linitis group were significantly different from those from the control group with a lower age at diagnosis, a more advanced histological lesion, a more frequent undiagnosed peritoneal carcinomatosis, and a higher risk of R1 resection. Sensitivity and specificity of CT scan for the diagnosis of lymph node involvement were $44 \%$ and $75 \%$, respectively, in the linitis plastica group and $55 \%$ and $60 \%$, respectively, in the control group. The sensitivity and specificity of CT scan for the T3-T4 parietal invasion were $26 \%$ and $100 \%$, respectively, in the linitis group and $40 \%$ and $72 \%$, respectively, in the control group.

Conclusion: CT scan has an equal sensitivity and specificity for the evaluation of lymph node and parietal involvement in gastric adenocarcinoma, including linitis plastica. CT scan remains the cornerstone of preoperative evaluation in gastric adenocarcinoma, including linitis plastica. However, CT presents a lack of sensitivity to diagnose low-volume peritoneal carcinomatosis. Keywords: computed tomography, CT scan, linitis, gastric adenocarcinoma

\section{Introduction}

Gastric adenocarcinoma is a frequent disease and the fifth most frequent cancer in the world with 951,000 new cases in 2012. This pathology has a poor prognosis and it is the third cause of cancer death in the world with 723,000 deaths in 2012. The incidence of this cancer varies among geographical areas and is higher in Japan, China, Eastern Europe, and South America, while it remains low in North America, Northern Europe, and Africa. ${ }^{1}$ In 2015, in the USA, 26,370 new cases were reported for this cancer which also accounted for 10,730 deaths. ${ }^{2}$ In France, the incidence is estimated at 6,550 new cases per year, representing the fourth cause of digestive cancer and is responsible for 4,410 deaths per year, which is the fourth leading cause of cancer death.

In gastric adenocarcinoma, the presence of independent cells is found in almost a quarter of cases. ${ }^{3}$ Independent cells correspond to muco-secreting adenocarcinoma cells, the cells that are rich in mucin and have lost their adhesion capacity by loss of 
expression of a membrane protein, E-cadherin, secondary to a mutation of the E-cadherine (cdh1) gene. The presence of independent cells is associated with a higher incidence of lymph node involvement. ${ }^{3}$

Gastric linitis plastica accounts for $\sim 10 \%-15 \%$ of gastric cancers and presents particular characteristics compared to "classic" adenocarcinoma: a lower median age at diagnosis, no male predisposition (sex ratio 1.1), a higher proportion of body, and antrum or pangastric lesions. ${ }^{3-5}$ On endoscopy, a rigid stomach aspect with large folds that do not disappear on insufflation characterizes gastric linitis plastica. The lesion is mainly circumferential and its presentation resembles that of a linen cloth, thereby explaining the etymology of the term described for the first time by Brinton in 1865. The diagnosis of gastric linitis plastica is histological (Figure 1A and B) and requires the association of independent cells and a dense desmoplastic reaction in the submucosal layer. The macroscopic examination reveals a thick, fibrous, and indurated wall. The abdomino-pelvic computed tomography (CT) scan is the essential examination in the preoperative assessment of gastric adenocarcinoma, including linitis plastica. ${ }^{6,7}$

The initial assessment is a crucial step in the management of patients due to various therapeutic options in nonmetastatic forms ranging from neoadjuvant chemotherapy to primary gastrectomy. ${ }^{6-8}$ Therefore, the diagnostic performance of CT scan is decisive. In gastric cancers, the improvement of tomodensitometric techniques in recent decades has allowed better identification of secondary lesions. Several studies have confirmed good sensitivity $(80 \%-90 \%)$ and even greater specificity $(95 \%-97 \%)$ of the CT scan with water gastric distension for the evaluation of parietal invasion and lymph node extension. ${ }^{9,10}$

In the pretherapeutic assessment of gastric adenocarcinoma, scientific societies (the European Society for Medical Oncology and National Thesaurus of Digestive Oncology) recommend a CT scan. It allows the detection of both lymph node involvement and metastasis and enables evaluation of resectability ${ }^{6,7}$ However, CT scan sensibility and specificity have never been correlated to the pathological results in gastric linitis plastica.

We herein report on a retrospective multicentric French matched study which assessed the performance of preoperative abdominal CT in gastric linitis plastica.

\section{Methods}

A retrospective multicentric French matched study was conducted on patients treated for gastric adenocarcinoma and who had undergone resection. Inclusion period ranged from January 1, 2006 to December 31, 2015. Four centers took part in this study and were based in France: Cochin University Hospital and Saint-Louis Hospital in Paris and Edouard Herriot Hospital and Jean Mermoz Clinic in Lyon. All patients resected following the diagnosis of nonmetastatic gastric linitis plastica and treated during the study period were included (Figure 1). The inclusion criteria were as follows: aged $>18$ years, endoscopic diagnosis of linitis plastica with histological confirmation, absence of distant metastases, and total or partial gastrectomy with lymph node dissection. Flow chart is presented in Figure 2. Total or partial gastrectomies performed for gastric adenocarcinoma over the aforementioned inclusion period were identified. Patients with a gastric linitis plastica diagnosis on histological report were included in the linitis plastica group. Patients with no available preoperative CT scan were secondarily excluded. Patients were matched to the TNM stage and the center at the rate of two patients per case of linitis plastica. Two groups were established: the linitis plastica group and the control group. Pathological findings that did not conform to AJCC 2010 classification were reviewed in order to achieve harmonization of histological classifications. ${ }^{11}$ The exclusion
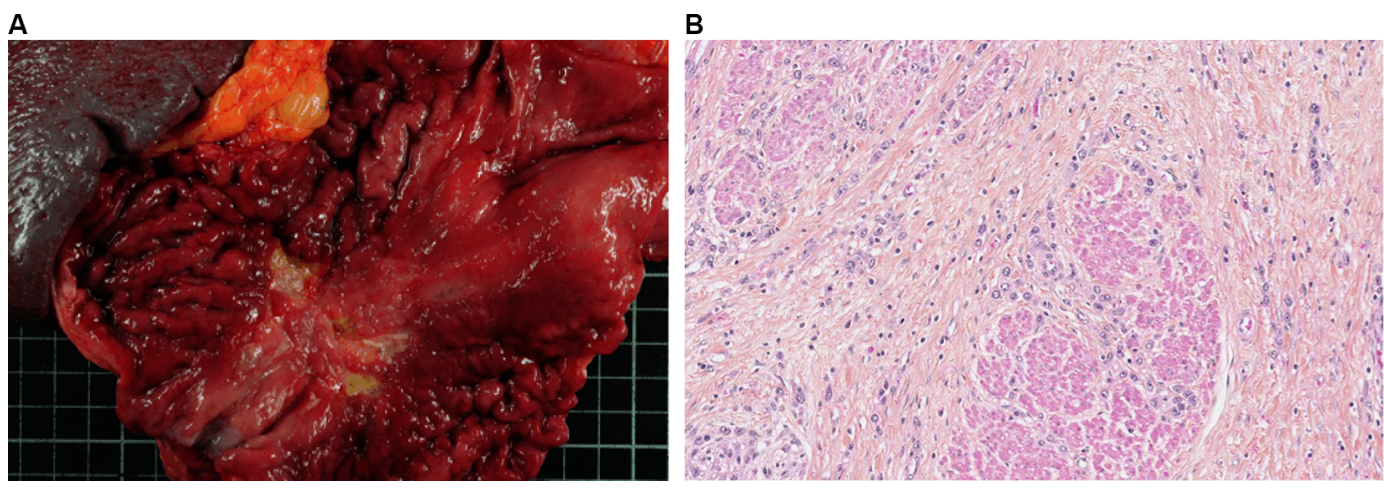

Figure I Macroscopic aspect of linitis plastica with rigid large folds $(\mathbf{A})$ and microscopic aspect of linitis plastica with a dense desmoplastic reaction (B). 


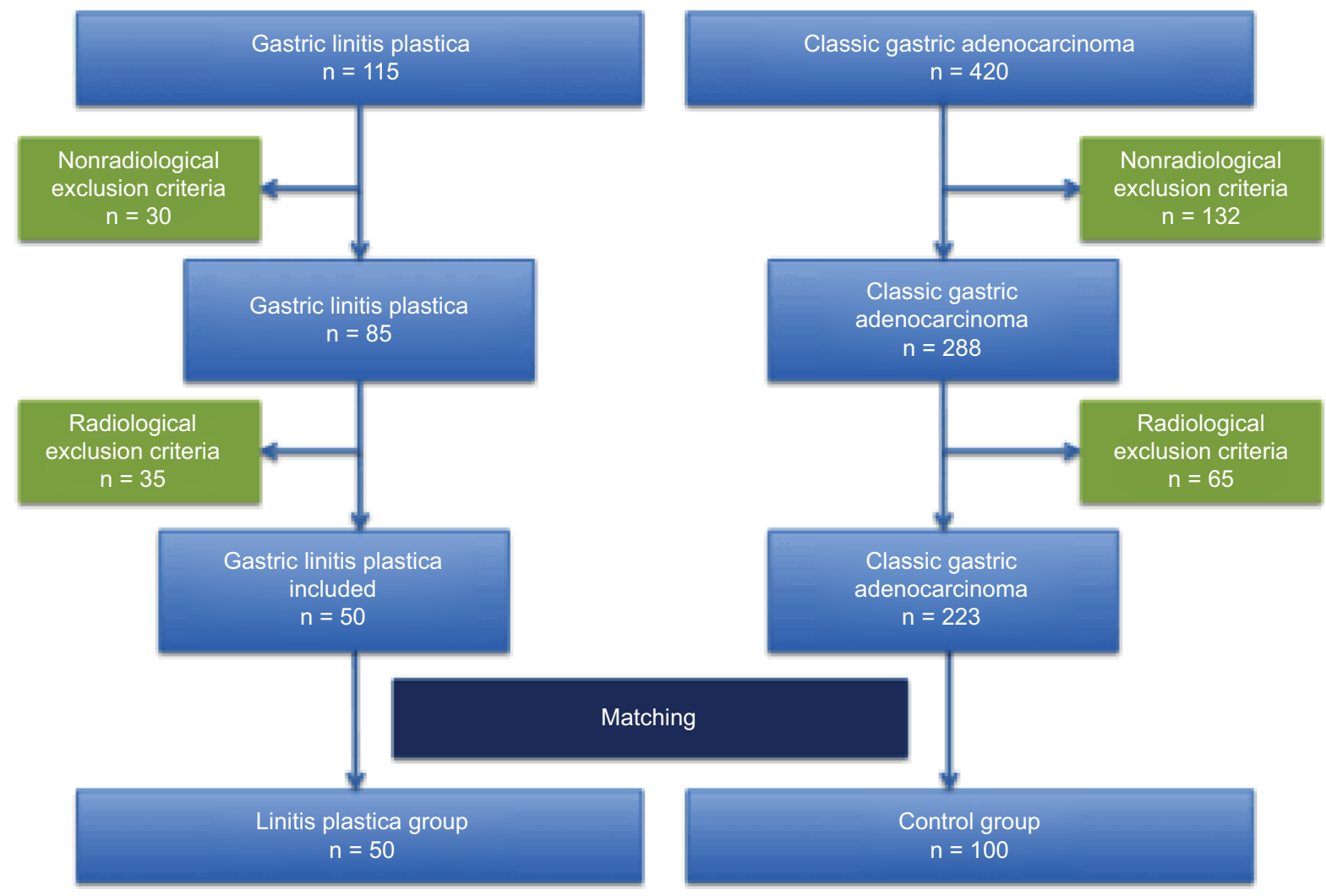

Figure 2 Flow chart of the study.

criteria were a history of gastric surgery, invasive endoscopic procedure on the stomach (mucosectomy, cystogastrostomy, digestive prostheses), esophago-gastric radiotherapy, Lynch's syndrome, germline cdh1 mutation, esophageal tumor (classified Siewert 1), mixed tumor with neuroendocrine contingent, association with gastric lymphoma, preoperative CT scan not available or not meeting the inclusion criteria listed earlier, and allergies to the iodinated contrast agent. The fortuitous discovery of a gastric stromal tumor on the surgical specimen was not an exclusion criterion. Patients were treated in accordance with the Helsinki Declaration, and the Cochin Local Ethic Committee approved the study (CLEP decision: AAA-2016-026001). All data were anonymously collected and, according to the Loi Jardé, no patient consent was needed, as the treatment implemented in this study was the standard, recommended therapy.

\section{Definition of linitis plastica}

Linitis plastica is defined, on gastrectomy piece, by the presence of a major contingent ( $>50 \%$ ) of independent cells and an abundant desmoplastic reaction. When the stromal reaction was not described in the histological report, the diagnosis was considered positive if the endoscopic aspect was evocative with an infiltrated aspect of the wall, presence of large folds that do not disappear upon insufflation or if the endoscopic ultrasound identified a thickened wall in the third layer at an early stage, or the disappearance or fusion of layers at a later stage associated with a diffuse or circumferential lesion.

\section{CT modalities}

Two independent radiologists, who were experts in digestive oncology, reviewed all abdomino-pelvic CT scans centrally. A radiologist was considered an expert in digestive oncology if he had read more than 2,000 digestive cancer CT scans. The procedure for performing abdomino-pelvic CT scan for stomach cancer was standardized. All centers had a multi-bar scanner with at least 64 strips. The thickness of the slices was set between $1 \mathrm{~mm}$ and $5 \mathrm{~mm}$ with a reconstruction of 1.5 $\mathrm{mm}$ every $1 \mathrm{~mm}$ or $1 \mathrm{~mm}$ every $0.6 \mathrm{~mm}$. All CT scans were first conducted with no injection; then, "arterial" phase and "portal" phase images were acquired after the injection of iodinated contrast agent defined by an acquisition performed 60-75 seconds after injection of the contrast agent. The selection of the iodinated contrast agent was left to the discretion of the center. By way of example, Cochin Hospital made a

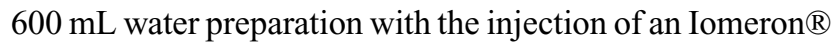
iodine contrast agent at a flow rate of $2.5 \mathrm{~mL}$ per second for a total volume of $90 \mathrm{~mL}$. Radiological data collected were 
TNM-staged according to the AJCC 2010 classification, ${ }^{11}$ maximum thickness of the wall in tumor zone, number of lymph nodes involved, size and location of the largest suspect lymph node, and presence of secondary lesions and their locations.

\section{Statistical analysis}

The comparison of quantitative values was performed using the Student's $t$-test. The comparison of qualitative values was performed using the Fisher's test. The difference was considered significant with an alpha risk defined arbitrarily at 5\%.

\section{Results}

Fifty and 100 patients were included in the linitis plastica and in the adenocarcinoma groups, respectively (Figure 2). The median age at diagnosis was 60 and 67 years in the linitis plastica group and in the adenocarcinoma group, respectively $(p=0.02)$. Patients' characteristics are described in Table 1. No case of pangastric disease was reported in the control group versus $20 \%$ in the linitis plastica group $(p<0.01)$. Cardial or fundic involvement was less frequent in the linitis plastica group than in the control group $(12 \%$ vs $36 \%, p<0.01)$.

In the linitis plastica group, no patients with a pT0-2 lesion were considered to have an advanced lesion (ctT3-4) on CT scan, whereas these accounted for $28 \%$ of patients in the control group (Table 2). Sensitivity and specificity of preoperative CT scan to identify an advanced wall involvement (T3-4) were $26 \%$ and $100 \%$ in the linitis plastica group and $40 \%$ and $72 \%$ in the control group, respectively (Table 3 ).

Forty-four percent and $55 \%$ of patients with a histologic lymph node invasion $(\mathrm{pN}+)$ were identified with a CT scan lymph node invasion (ctN+) in the linitis plastica and in the adenocarcinoma groups, respectively. Sensitivity

Table I Characteristics of patients

\begin{tabular}{|c|c|c|c|c|c|}
\hline \multirow{2}{*}{$\begin{array}{l}\text { Parameter } \\
\mathbf{N}\end{array}$} & \multicolumn{2}{|c|}{ Linitis plastica group } & \multicolumn{2}{|c|}{ Control group } & \multirow[t]{2}{*}{ p-value } \\
\hline & \multicolumn{2}{|c|}{50} & \multicolumn{2}{|c|}{100} & \\
\hline Median age at diagnosis, years (min-max) & \multicolumn{2}{|c|}{$60(22-82)$} & \multicolumn{2}{|c|}{$67(35-90)$} & 0.02 \\
\hline Sex: male/female (\%) & \multicolumn{2}{|c|}{$54 / 46$} & \multicolumn{2}{|c|}{$66 / 34$} & 0.16 \\
\hline \multicolumn{6}{|l|}{ Center, n (\%) } \\
\hline University hospital & 36 & $(72)$ & 72 & $(72)$ & - \\
\hline Clinics & 14 & $(28)$ & 28 & $(28)$ & \\
\hline Neoadjuvant treatment, $\mathbf{n}(\%)$ & 28 & $(56)$ & 64 & $(64)$ & 0.72 \\
\hline \multicolumn{6}{|l|}{ Characteristics of the tumor, $n$ (\%) } \\
\hline Location & & & & & $<0.01$ \\
\hline Cardia/fundus & 6 & $(12)$ & 36 & $(36)$ & \\
\hline Body & 14 & $(28)$ & 22 & $(22)$ & \\
\hline Antrum/pylorus & 20 & $(40)$ & 42 & $(42)$ & \\
\hline Pangastrique & 10 & (20) & - & - & \\
\hline Surgery & & & & & $<0.01$ \\
\hline Partial gastrectomy & 6 & $(12)$ & 47 & $(47)$ & \\
\hline Total gastrectomy & 44 & (88) & 53 & (53) & \\
\hline Resection & & & & & $<0.01$ \\
\hline Ro & 36 & $(72)$ & 91 & (91) & \\
\hline RI & 14 & (28) & 9 & (9) & \\
\hline \multicolumn{6}{|l|}{ pTNM } \\
\hline pT0 & I & (2) & - & - & $<0.01$ \\
\hline $\mathrm{PTI}$ & 2 & (4) & 11 & (II) & \\
\hline $\mathrm{PT} 2$ & 5 & $(10)$ & 14 & (14) & \\
\hline PT3 & 21 & $(42)$ & 57 & (57) & \\
\hline pT4 & 21 & $(42)$ & 18 & (I8) & \\
\hline pNo & 16 & $(32)$ & 35 & (35) & 0.01 \\
\hline $\mathrm{pN}+$ & 34 & (68) & 65 & (65) & \\
\hline $\mathrm{pNI}$ & 9 & (18) & 30 & (30) & \\
\hline $\mathrm{pN} 2$ & 7 & (14) & 22 & $(22)$ & \\
\hline $\mathrm{pN} 3$ & 18 & (36) & 13 & (13) & \\
\hline Mo & 40 & $(80)$ & 95 & (95) & $<0.01$ \\
\hline$M I^{a}$ & 10 & $(20)$ & 5 & (5) & \\
\hline
\end{tabular}

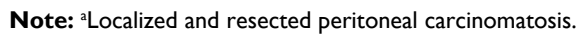


Table 2 Correlation between radiological and histological staging of parietal invasion in the linitis plastica group and in the control group

\begin{tabular}{|c|c|c|c|c|c|c|c|c|c|c|c|c|c|c|c|c|c|}
\hline & & \multicolumn{16}{|c|}{ Histological stage } \\
\hline & & \multicolumn{8}{|c|}{ Linitis plastica group $(n=50)$} & \multicolumn{8}{|c|}{ Control group $(n=100)$} \\
\hline & & pTO & pTI & pT2 & pT0-2 & pT3 & pT4 & pT4-3 & Total & pTO & PTI & pT2 & pT0-2 & pT3 & pT4 & pT4-3 & Total \\
\hline \multirow{6}{*}{$\begin{array}{l}\text { Radiological } \\
\text { stage }\end{array}$} & ctTo & - & - & - & \multirow[t]{3}{*}{16} & - & - & \multirow[t]{3}{*}{62} & - & - & - & - & \multirow[t]{3}{*}{18} & - & - & \multirow[t]{3}{*}{45} & - \\
\hline & ctTI & - & - & 2 & & 6 & - & & 8 & - & 5 & 1 & & 3 & 3 & & 12 \\
\hline & ctT2 & 2 & 4 & 8 & & 26 & 30 & & 70 & - & 4 & 8 & & 33 & 6 & & 51 \\
\hline & ctT3 & - & - & - & \multirow[t]{2}{*}{0} & 10 & 12 & \multirow[t]{2}{*}{22} & 22 & - & 2 & 5 & \multirow[t]{2}{*}{7} & 21 & 8 & \multirow[t]{2}{*}{30} & 36 \\
\hline & ctT4 & - & - & - & & - & - & & 0 & - & - & - & & - & 1 & & 1 \\
\hline & Total & 2 & 4 & 10 & 16 & 42 & 42 & 84 & 100 & - & 11 & 14 & 25 & 57 & 18 & 75 & 100 \\
\hline
\end{tabular}

Notes: Values are expressed in percentage. The shading corresponds to the correlation of the radiological evaluation and the histological evaluation.

Table 3 Predictive performance of abdominal computed tomography scan in the staging of parietal, lymph node, and metastatic invasion in the linitis plastica group and in the control group

\begin{tabular}{lll}
\hline & $\begin{array}{l}\text { Linitis plastica } \\
\text { group }\end{array}$ & $\begin{array}{l}\text { Control } \\
\text { group }\end{array}$ \\
\hline T (T0-2 vs T3-4) & 26 & \\
Sensibility & 100 & 40 \\
Specificity & 100 & 72 \\
Positive predictive value & 21 & 81 \\
Negative predictive value & & 29 \\
N & 44 & \\
Sensibility & 75 & 55 \\
Specificity & 79 & 60 \\
Positive predictive value & 39 & 72 \\
Negative predictive value & & 42 \\
M & - & \\
Sensibility & 90 & 20 \\
Specificity & - & 91 \\
Positive predictive value & 78 & 10 \\
Negative predictive value & & 96 \\
\hline Note: Vartes
\end{tabular}

Note: Values are expressed in percentage.

and specificity of preoperative CT scan to identify a lymph node invasion were $44 \%$ and $75 \%$, respectively, in the linitis plastica group and $55 \%$ and $60 \%$, respectively, in the control group (Table 3 ).

Zero percent and $20 \%$ of patients with a histologic metastatic invasion ( $\mathrm{pM}+$ ) were identified as such with the CT scan in the linitis plastica and in the adenocarcinoma groups, respectively (Table 4). Sensitivity and specificity of preoperative abdominal CT scan in the assessment of metastatic invasion (ctM+) were $0 \%$ and $90 \%$, respectively, in the linitis plastica group and $20 \%$ and $91 \%$, respectively, in the control group.

\section{Discussion}

In the present study, we evaluated for the first time in a linitis plastica population the preoperative CT scan specificity of $75 \%, 100 \%$, and $90 \%$ for the evaluation of lymph node, parietal, and metastatic tumor involvement, respectively, compared to the specificity of $60 \%, 72 \%$, and $91 \%$, respectively, in the control group. We identified noninferior sensitivity and specificity of the CT scan in both the groups, reinforcing the usefulness of a CT scan evaluation in all gastric adenocarcinoma cases, including those of linitis plastica.

In our study, we identified several characteristics observed in the linitis plastica group, such as a lower age at diagnosis, stomach lesions which were more distal (body and antropyloric location), a greater proportion of diffuse lesions, and being female (not significant) when compared with those observed in classic gastric adenocarcinoma. These characteristics are in line with published epidemiology of linitis plastica. ${ }^{4,12,13}$ Piessen et al also found in their study a younger age at diagnosis with $53.1 \%$ of patients below 60 years of age diagnosed in signet ring cell carcinoma group versus $34.2 \%$ in nonsignet ring cell carcinoma group $(p<0.01) .{ }^{12}$ Liu et al identified a significant difference with a male/female sex ratio of 1.4 in the signet ring cell carcinoma group versus 2.4 in the nonsignet ring cell carcinoma group $(p<0.01){ }^{4}$ Liu et al also reported a significantly higher rate of distal and diffuse stomach involvement in the signet ring cell carcinoma group (49\% lower third and 10\% diffuse vs $42 \%$ and $5 \%$, respectively, in the nonsignet ring cell carcinoma group, $p<0.01){ }^{4}$

In the linitis plastica group, we showed a significantly higher rate of advanced tumors, classified as pT4, pN3, and R1, compared to the control group. Similarly, the rate of peritoneal carcinomatosis, undiagnosed by preoperative extension assessment, was significantly higher in the linitis plastica group. Peritoneal carcinomatosis refers to minor invasions that are either underestimated on CT or undetectable. Our data are in agreement with the literature suggesting that more advanced tumors present parietal invasion, lymph node involvement, and peritoneal levels in gastric linitis plastica. ${ }^{3,4,12,14}$ Liu et al identified a higher rate of stage III tumors (T2N3 or T3N2-3 or T4 N1-3) in the signet 
Table 4 Correlation between radiological and histological staging of lymph node and metastatic invasion in the linitis plastica group and in the control group

\begin{tabular}{|c|c|c|c|c|c|c|c|c|c|c|c|}
\hline & & \multicolumn{10}{|c|}{ Histological stage } \\
\hline & & \multicolumn{5}{|c|}{ Linitis plastica group } & \multicolumn{5}{|c|}{ Control group } \\
\hline & & pNo & pN+ & pMO & pM+ & Total & pNo & pN+ & pMO & pM+ & Total \\
\hline \multirow{5}{*}{$\begin{array}{l}\text { Radiological } \\
\text { stage }\end{array}$} & ctNo & 24 & 38 & - & - & 62 & 21 & 29 & - & - & 50 \\
\hline & ctN+ & 8 & 30 & - & - & 38 & 14 & 36 & - & - & 50 \\
\hline & ctMO & - & - & 72 & 20 & 92 & - & - & 86 & 4 & 90 \\
\hline & ctM+ & - & - & 8 & 0 & 8 & - & - & 9 & 1 & 10 \\
\hline & Total & 32 & 68 & 80 & 20 & 100 & 35 & 65 & 95 & 5 & 100 \\
\hline
\end{tabular}

Notes: Values are expressed in percentage. The shading corresponds to the correlation of the radiological evaluation and the histological evaluation.

ring cell carcinoma group compared to the nonsignet ring cell carcinoma group (65\% vs $52 \%, p<0.01) .{ }^{4}$ Piessen et al reported higher rates of pT3-4 parietal invasion (30\% vs $17 \%, p<0.01$ ), lymph node invasion ( $63 \%$ vs $49 \%, p<0.01$ ), number of lymph nodes invaded ( 9.6 vs $4.2, p<0.01$ ), and positive margin rates ( $\mathrm{R} 1$ and $\mathrm{R} 2,44 \%$ vs $26 \%, p=0.02$ ) in the signet ring cell carcinoma group compared to the nonsignet ring cell carcinoma group. ${ }^{12,14}$

On radiological evaluation of preoperative lymph node involvement, lesions were correctly classified as $\mathrm{pN}+$ in $44 \%$ of cases in the linitis plastica group and 55\% in the control group. Similarly, Balthazar et al showed in a retrospective study conducted from 1986 to 1994 and without a control group that CT correctly identified $64 \%$ of lesions classified histologically as $\mathrm{pN}+$ in a small series of linitis plastica patients. ${ }^{15}$ Lee et al reported a wide range of sensitivity (from $57 \%$ to $96 \%$ ) and specificity (from $57 \%$ to $71 \%$ ) for the assessment of lymph node invasion in gastric adenocarcinomas by $\mathrm{CT}$ scan without distinction in the histologic subtype. ${ }^{16}$

In our study, we identified a trend for an underestimation of the CT on the parietal involvement in all groups. In the linitis plastica group, all (100\%) pT0-2 lesions and 26\% of pT3-4 lesions were correctly classified. In the control group, the proportion was $72 \%$ and $40 \%$, respectively. Balthazar et al showed that abdominal CT correctly identified serosal invasion in $67 \%$ of cases compared to $38 \%$ in our study. ${ }^{15}$ The discrepancy might be explained by some limitations from both studies. One of the limitations could be the quality of the examination because it appeared that the gastric distension with water was not optimal or not systematically achieved in our study. The evaluation of the parietal invasion depends on the quality of the CT scan. Water distention has been shown to improve performance of this examination in the assessment of wall invasion. ${ }^{9,10,17}$ Kumano et al reported excellent sensitivities ( $90 \%$ for operator 1 and $80 \%$ for operator 2 ) and specificities ( $95 \%$ and $97 \%$, respectively) for the evaluation of parietal invasion with a protocol involving sensitization by ingestion of $600 \mathrm{~mL}$ of water 5 minutes before the examination. ${ }^{9}$ Our results argue for a standardized CT scan with water distension.

In our study, we failed to identify peritoneal carcinomatosis in all cases from the linitis plastica group. The proportion of identification rose to $20 \%$ in the gastric adenocarcinoma group. It should be noted that all patients in this study were considered nonmetastatic and resectable at the initial extension assessment. Lee et al reported a range for sensitivity (from $58 \%$ to $75 \%$ ) and specificity (from $80 \%$ to $83 \%$ ) of metastatic invasion assessment by $\mathrm{CT}$ scan in gastric adenocarcinomas without distinction in the histologic subtype. ${ }^{16}$

Our study presents some limitations considering that it was a retrospective analysis based on patients who received surgery. While on the one hand, the retrospective nature of the study allowed to confirm all patients included in the evaluated group, and on the other hand, it resulted in an exclusion of $73 \%$ of cases identified as potential linitis plastica cases (Figure 2).

\section{Conclusion}

The abdominal CT scan has similar sensitivity and specificity for the evaluation of lymph node and parietal invasion in the linitis plastica group and the control group. It remains the cornerstone of preoperative assessment in gastric adenocarcinoma, including linitis plastica. However, CT scan suffers from a lack of sensitivity to diagnose low-volume peritoneal carcinomatosis. Physicians might take into consideration the efficacy of CT scan in preoperative settings, and an exploratory laparoscopy should be proposed in case of gastric linitis plastica considering the strong propensity for peritoneal extension.

\section{Disclosure}

The authors report no conflicts of interest in this work. 


\section{References}

1. Ferlay J, Soerjomataram I, Dikshit R, et al. Cancer incidence and mortality worldwide: sources, methods and major patterns in GLOBOCAN 2012. Int J Cancer. 2015;136(5):E359-E386.

2. Siegel RL, Miller KD, Jemal A. Cancer statistics, 2016. CA Cancer J Clin. 2016;66(1):7-30.

3. Taghavi S, Jayarajan SN, Davey A, Willis AI. Prognostic significance of signet ring gastric cancer. J Clin Oncol. 2012;30(28):3493-3498.

4. Liu X, Cai H, Sheng W, et al. Clinicopathological characteristics and survival outcomes of primary signet ring cell carcinoma in the stomach: retrospective analysis of single center database. PLoS One. 2015;10(12):e0144420.

5. Zhang M, Zhu G, Zhang H, Gao H, Xue Y. Clinicopathologic features of gastric carcinoma with signet ring cell histology. J Gastrointest Surg. 2010;14(4):601-606.

6. Coburn N, Seevaratnam R, Paszat L, et al. Optimal management of gastric cancer: results from an international RAND/UCLA expert panel. Ann Surg. 2014;259(1):102-108.

7. Van Cutsem E, Dicato M, Geva R, et al. The diagnosis and management of gastric cancer: expert discussion and recommendations from the 12th ESMO/World Congress on Gastrointestinal Cancer, Barcelona, 2010. Ann Oncol. 2011;22 (Suppl 5):v1-v9.

8. Cunningham D, Allum WH, Stenning SP, et al. Perioperative chemotherapy versus surgery alone for resectable gastroesophageal cancer. N Engl J Med. 2006;355(1):11-20.
9. Kumano S, Murakami T, Kim T, et al. T staging of gastric cancer: role of multi-detector row CT. Radiology. 2005;237(3):961-966.

10. Chen C-Y, Hsu J-S, Wu D-C, et al. Gastric cancer: preoperative local staging with $3 \mathrm{D}$ multi-detector row CT-correlation with surgical and histopathologic results. Radiology. 2007;242(2):472-482.

11. Washington K. 7th edition of the AJCC cancer staging manual: stomach. Ann Surg Oncol. 2010;17(12):3077-3079.

12. Piessen G, Amielh D, Messager M, et al. Is pretreatment endoscopic biopsy a good predictor of signet ring cell histology in gastric carcinoma? World J Surg. 2012;36(2):346-354.

13. Voron T, Messager M, Duhamel A, et al. Is signet-ring cell carcinoma a specific entity among gastric cancers? Gastric Cancer. 2015;21(40): $11428-11438$.

14. Piessen G, Messager M, Leteurtre E, Jean-Pierre T, Mariette C. Signet ring cell histology is an independent predictor of poor prognosis in gastric adenocarcinoma regardless of tumoral clinical presentation. Ann Surg. 2009;250(6):878-887.

15. Balthazar EJ, Siegel SE, Megibow AJ, Scholes J, Gordon R. CT in patients with scirrhous carcinoma of the GI tract: imaging findings and value for tumor detection and staging. AJR Am J Roentgenol. 1995;165(4):839-845.

16. Lee DH, Kim SH, Joo I, Hur BY, Han JK. Comparison between 18FFDG PET/MRI and MDCT for the assessment of preoperative staging and resectability of gastric cancer. Eur J Radiol. 2016;85(6):1085-1091.

17. Kwee RM, Kwee TC. Imaging in local staging of gastric cancer: a systematic review. J Clin Oncol. 2007;25(15):2107-2116.
Cancer Management and Research

\section{Publish your work in this journal}

Cancer Management and Research is an international, peer-reviewed open access journal focusing on cancer research and the optimal use of preventative and integrated treatment interventions to achieve improved outcomes, enhanced survival and quality of life for the cancer patient. The manuscript management system is completely online and includes

\section{Dovepress}

a very quick and fair peer-review system, which is all easy to use. Visit http://www.dovepress.com/testimonials.php to read real quotes from published authors. 